\title{
Debris flow modelling in Julian Alps using FLO-2D
}

\author{
C. Calligaris, M. A. Boniello \& L. Zini \\ Department of Geological, Environmental and Marine Sciences, \\ Trieste University, Italy
}

\begin{abstract}
Val Canale Valley is located in the Italian Julian Alps, in the north-eastern corner of Friuli Venezia Giulia Region. On 29 August 2003, the area has been invested by a strong intensity meteorological event (rainfall maxima from Pontebba station, which recorded the highest rainfall depths, were characterised by return periods in the range of 500-1000 years for 3-h, 6-h and 12-h periods) that caused debris flow phenomena. These have damaged infrastructures and killed people. In collaboration with the Geological Service of Friuli Venezia Giulia Region and with the contribution, for the input data, of the Department of Territory and Sour-Forest Systems of the University of Padova, we investigated twelve river basins located in the studied valley with different geologicalgeomorphological characteristics. The main objective of the study is to model the debris flow phenomena. This goal has been obtained using FLO-2D software. In all the basins implicated, we have collected samples for grain size curve distributions and rheological analyses in order to characterize the detritical material. First of all it has been necessary to execute a back analysis study with the aim of better define all the parameters involved. Subsequently, the goal has been to simulate a new alluvional event with a return time of 200 years, on the basis of actual morphology obtained from laser scan data (where data have been available) realizing a DEM based on a grid cell size of $5 \mathrm{~m}$. On this topographic base it has been possible to insert the defence infrastructures realized after the alluvional event. From all this input data it has been possible to model and to simulate the potential debris flow with the aim to obtain, vulnerability first, and hazard mapping later, necessary for the future territorial planning.

Keywords: debris flow, FLO-2D, mitigating measures, Alps, territorial planning.
\end{abstract}




\section{Introduction}

During the last 20 years, in the alpine region, several severe meteorological events have caused debris flow phenomena that have damaged the infrastructures causing problems to the tourist economy of the involved areas (Tropeano et al. [1]). The study area, Val Canale, is a north-east oriented valley located in the north-eastern part of Italy. The area is of a great interest from a geological point of view because of different formations interested by faults and structural dislocations, elevated slopes and a high rate of urbanization considering that it is an highly seismic mountain area. All these factors induced the researchers of the University of Trieste (Department of Geological, Environmental and Marine Sciences) to consider the area as a good test site for simulate, with FLO-2D, a scenario of debris flow phenomena with a return time of 200 years. FLO-2D software is based on a quadratic shear stress model (O'Brien and Julien [2]) and it is considered the most appropriate modelling software to describe the continuum of flow regimes from viscous to turbulent/dispersive flows (Tecca et al. [3]). We presents numerical modelling of 12 debris flow events already occurred that with their sediment loads remarkable property damages. As a first step it has been necessary to calibrate the software using field data (references documentation, geological surveys and grain size analyses) to realize 12 backanalyses for every single basin. As second step, the parameter values obtained from back-analysis have been inserted in the software and it has been possible to define future flow directions. To complete the study it has been necessary to consider the mitigation works in order to better understand the possible directions of the flow in a potential future event. This is very useful tool for future planning for all the local Authorities.

\section{Description of the main flood event}

The area of Val Canale, Canal del Ferro and Val Aupa, as well as the entire part of the north-eastern Friuli Venezia Giulia Region, was interested by a high intensity rainfall on the $29^{\text {th }}$ August 2003. The rainfall started at 12 a.m., firstly affecting the upper sector of the mountain areas among Cucco, Malborghetto and Ugovizza villages, then it gradually moved downwards with increasing intensity. A total of $293 \mathrm{~mm}$ of rainfall was recorded by the Pontebba pluviometric station from 2 to 6 p.m. The rainfall and associated debris flow events $29^{\text {th }}$ August 2003 caused the death of two persons, 300 displaced and 260 damaged houses and it caused substantial damages to infrastructures that were made unavailable for several days. The mobilization of more than a thousand of landslides occurred along the studies sides. Hydrological analyses were performed using data recorded by Pontebba rain-gage. This instrument is part of the network managed by the Regional Directorate of Civil Defence. Data are available at an interval time of 30 minutes. Maximum values of $50,8 \mathrm{~mm}$ in 30 minutes (between 5 and 5.30 p.m.), $88.6 \mathrm{~mm}$ per hour (from 3.30 to 4.30 p.m), $233.4 \mathrm{~mm}$ in three hours (between 2.30 and 5.30 p.m.) and 343.0 in six hours (from 12 a.m. to 6 p.m.) were observed. The total influx of meteoric event, which lasted about 12 hours, 
was equal to $389.6 \mathrm{~mm}$. Regarding the payback time characterizing the event, there is a considerable variation dependent on the duration: between 1 and 24 hours, the time of delivery is between 50 and 100 years; for 12 hours it is between 200 and 500 years, while, for a period from 3 to 6 hours, payback time varies between 500 and 1000 years (Borga et al. [4]).

\section{Geological framework}

In the complexity of the event just described, twelve basins have been chosen from the local authorities to be studied. These basins are located in Val Canale valley and in smaller valleys next to it (Fig.1).

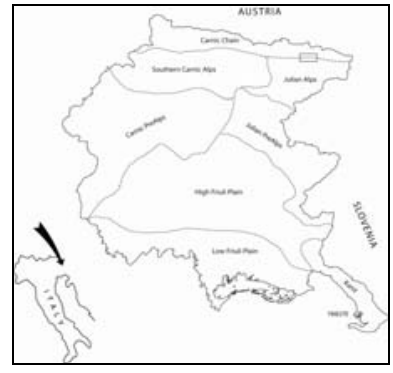

Figure 1: Area location.

The litostratigraphical units in the studied area are essentially represented by carbonate sedimentary units chronologically dated between Permian and Triassic often covered by loose recent deposits of Quaternary. Permian sediments are characterized by the Bellerophon Unit in which it is possible to associate dolomite and black limestones thickly stratified, that outcrops in the lower part of the valley. Triassic heterogeneous calcareous-terrigenus series (very stratified limestones and siltstones) made up the Werfen Unit. The Serla Unit overlaid the Werfen Unit being in direct tectonical contact. Serla is mainly composed of massive dolomite, dolomitic limestone, and less commonly by stratified limestones. Quaternary deposits are mostly represented in the lower part of the valley. According to their genesis, the deposits can be distinguished as gravitative, as detritical fans or screes, and deposits due to fluvial processes. Glacial deposits outcropping in different areas and having different stratigraphical positions are present in the entire studied area.

From a structural point of view, the tectonic features affecting the portion of territory are linked to the alpine orogeny and they are marked by wide monoclinal structures separated by east-west tectonic relocations. In the southern part of the investigated area, the monoclinal setting is affected from a regional displacing line called "Fella Sava", which has led the monoclinalic block to overtrust on a similar southernmost block. From the geomechanical point of view, stress associated with bending and faults have generated intense fracturation in the bedrock. The area is subjected to high seismicity and it is active from a tectonical point of view. 


\section{The numerical simulation}

\subsection{FLO-2D model}

FLO-2D is a 2-dimensional flood routing model of volume conservation that routes a flood hydrograph while predicting floodwave attenuation due to flood storage. Hyperconcentrated sediment flow is simulated by the FLO-2D model using a quadratic rheological model that includes viscous stress, yield stress, turbulence and dispersive stress terms as a function of sediment concentration. The model uses the full dynamic wave momentum equation and a central finite difference routing scheme with eight potential flow directions to predict the progression of a flood hydrograph over a system of square grid elements. Wave propagation is fully controlled by topography and roughness or resistance to flow. The model is suitable to simulate flooding of rivers and can also be used to analyze problems of flood flows as unconventional not confined on alluvial fan with complex topography, mud flow and debris flow, and floods event affecting urban areas (FLO-2D [5]). The FLO-2D model is an effective tool for the evaluation of hazard floods event and planning for mitigation measures, for this reason it has been decided to use it to analyze what happened and what could happen in the future.

\subsection{Software calibration through back analyses using twelve basins}

In order to simulate with good precision, both the flooded area and the thickness of debris deposits, for all the twelve basins, the catastrophic event has been replicated. These back analyses have permitted to calibrate the parameters involved in the simulations and to characterize every single debris flow. To obtain this, first of all, it has been necessary to evaluate the topographical settings consisting in information layers contained in the Regional Technical Numerical Chart supplied by Friuli Venezia Giulia Region at a scale of 1:5000. From this data it was possible to obtain a DTM with a cell size of $5 \times 5 \mathrm{~m}$. The DTM was imported in the FLO-2D pre-processor GDS and in this environment it has been created a computational domain having cell size of $5 \times 5 \mathrm{~m}$. The topography was verified and corrected where possible, in particular it was necessary to change the elevation of roads, houses and, generally, of all infrastructures. This permitted to have a DTM as similar as possible to realty. One of the most paramount input parameters, important as a good topographical base, was the inflow hydrograph. Data were studied in collaboration with the Department of Territory and Agro-Forestry Systems of the University of Padova. This has permitted the creation of a single hydrograph for each of the twelve studied basins. For every single basin a different sediment concentration by volume was assigned to the hydrograph. The range has been between 0.2 as a minimum and 0.60 corresponding to a mature flow. The Manning coefficient used was 0.1 (Tecca et al. [3]). The resistance parameter for laminar flow K was assumed among 24, 1000 and 2285 suggested values for debris flow (D'Agostino and Tecca [7]). Rheological parameters were mainly obtained from the literature (FLO-2D [5]). It has been possible to identify twelve pairs of 
potential rheological parameters (Table 1), and therefore twelve simulations were consequently performed for every single basin. A model is successfully calibrated when the simulation results are consistent with the observed flow behaviour in terms of extent of flooded area, runout distance, estimate of deposited sediment volume and flow depth (cfr D'Agostino). Among the twelve simulations, for each basin the most suitable has been chosen.

Table 1: Rheological parameters.

\begin{tabular}{|l|c|c|c|c|c|}
\hline $\begin{array}{l}\text { Simulations (back } \\
\text { analysis) }\end{array}$ & \multicolumn{2}{|c|}{$\eta$} & \multicolumn{2}{c|}{$\tau$} & Model used \\
\hline Name of basin & $\alpha$ & $\beta$ & $\alpha$ & $\beta$ & \\
\hline Simulation 01 & 0.036 & 22.1 & 0.181 & 25.7 & Aspen Pit 1 \\
\hline Simulation 02 & 0.0538 & 14.5 & 2.72 & 10.4 & Aspen Pit 2 \\
\hline Simulation 03 & 0.00136 & 28.4 & 0.152 & 18.7 & Aspen Natural Soil \\
\hline Simulation 04 & 0.128 & 12 & 0.0473 & 21.1 & Aspen Mine Fill \\
\hline Simulation 05 & 0.000495 & 27.1 & 0.0383 & 19.6 & Aspen Watershed \\
\hline Simulation 06 & 0.000201 & 33.1 & 0.291 & 14.3 & Aspen Mine Source Area \\
\hline Simulation 07 & 0.00283 & 23 & 0.0345 & 20.1 & Glenwood 1 \\
\hline Simulation 08 & 0.0648 & 6.2 & 0.0765 & 16.9 & Glenwood 2 \\
\hline Simulation 09 & 0.00632 & 19.9 & 0.000707 & 29.8 & Glenwood 3 \\
\hline Simulation 10 & 0.000602 & 33.1 & 0.00172 & 29.5 & Glenwood 4 \\
\hline Simulation 11 & 0.0075 & 14.39 & 2.6 & 17.48 & Dai et. al (1980) \\
\hline Simulation 12 & 0.0075 & 14.39 & 0.152 & 18.7 & Tecca et al. \\
\hline
\end{tabular}

\subsection{Prediction of debris flow hazard}

To use the results obtained whit the simulations as an useful tool for future planning for all the local Authorities, there has been the necessity to introduce, into the models the actual morphology and the mitigation structures already realized. New DTM were created using, where possible, laser scan data, and new structures, as depositional square, check dam, selective check dam, channels, river protection works and berms, were introduced manually, where necessary, into the GSD pre-processor module. To run the model, for each single basin, it was used the yield stress and the viscosity parameters obtained with the back analysis.

\section{Final remarks}

The application of the FLO-2D software to this kind of processes can improve the capability to predict debris flow behaviour and estimates depths and velocity, identify areas of inundation delineating hazard maps and design measures for hazard mitigations (Fig. 2 and Fig. 3) (Tecca et al. [3]). It is important to understand the conduct of the phenomena, in order to create several scenarios 
86 Monitoring, Simulation, Prevention and Remediation of Dense Debris Flows II
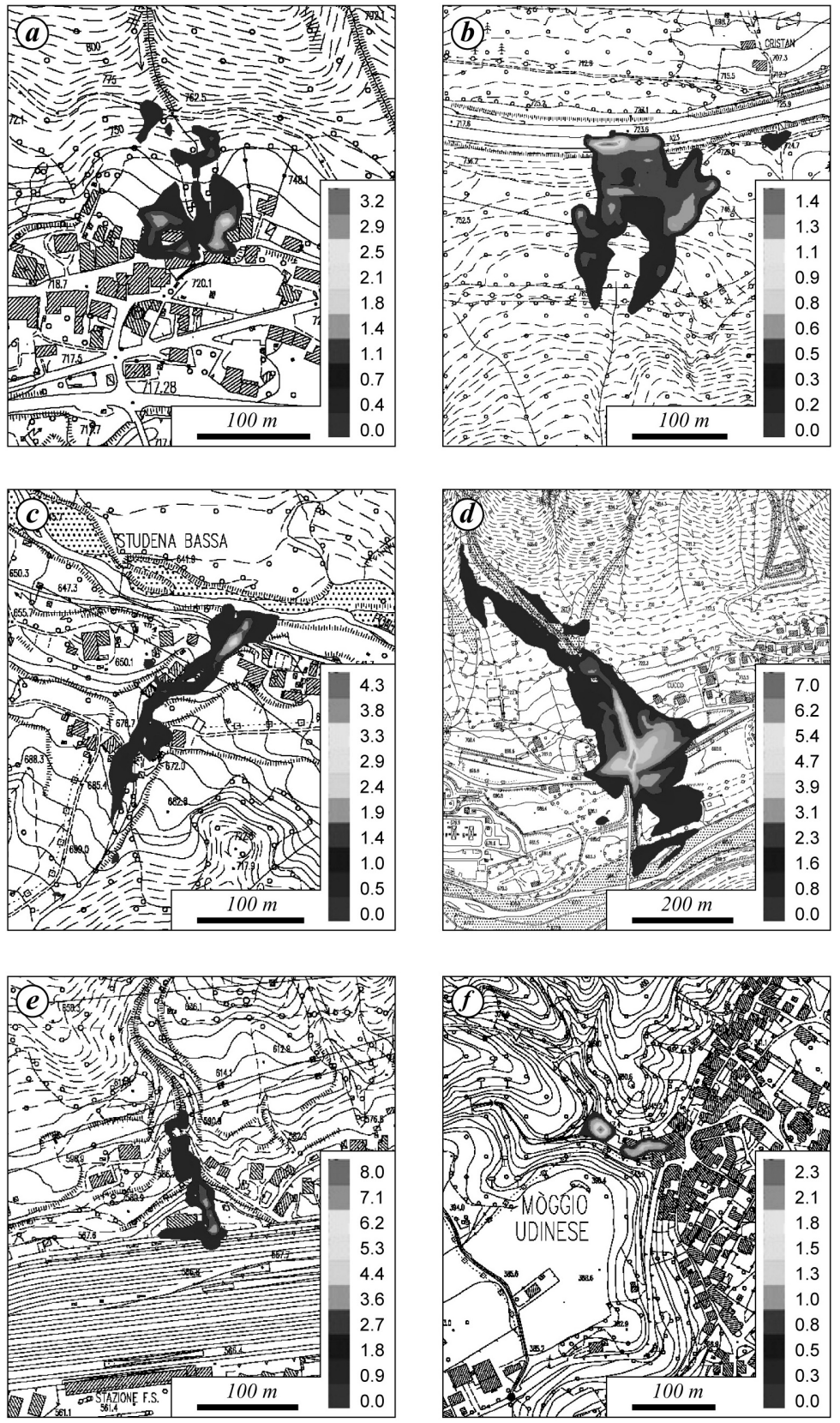

Figure 2: $\quad$ Final flow depth areas calculated for basins:a) Malborghetto Centro, b) Fella sinistra, c) Rio Ruscis, d) Rio Cucco, e) Rio Pontebba 1, f) Moggio Udinese. 

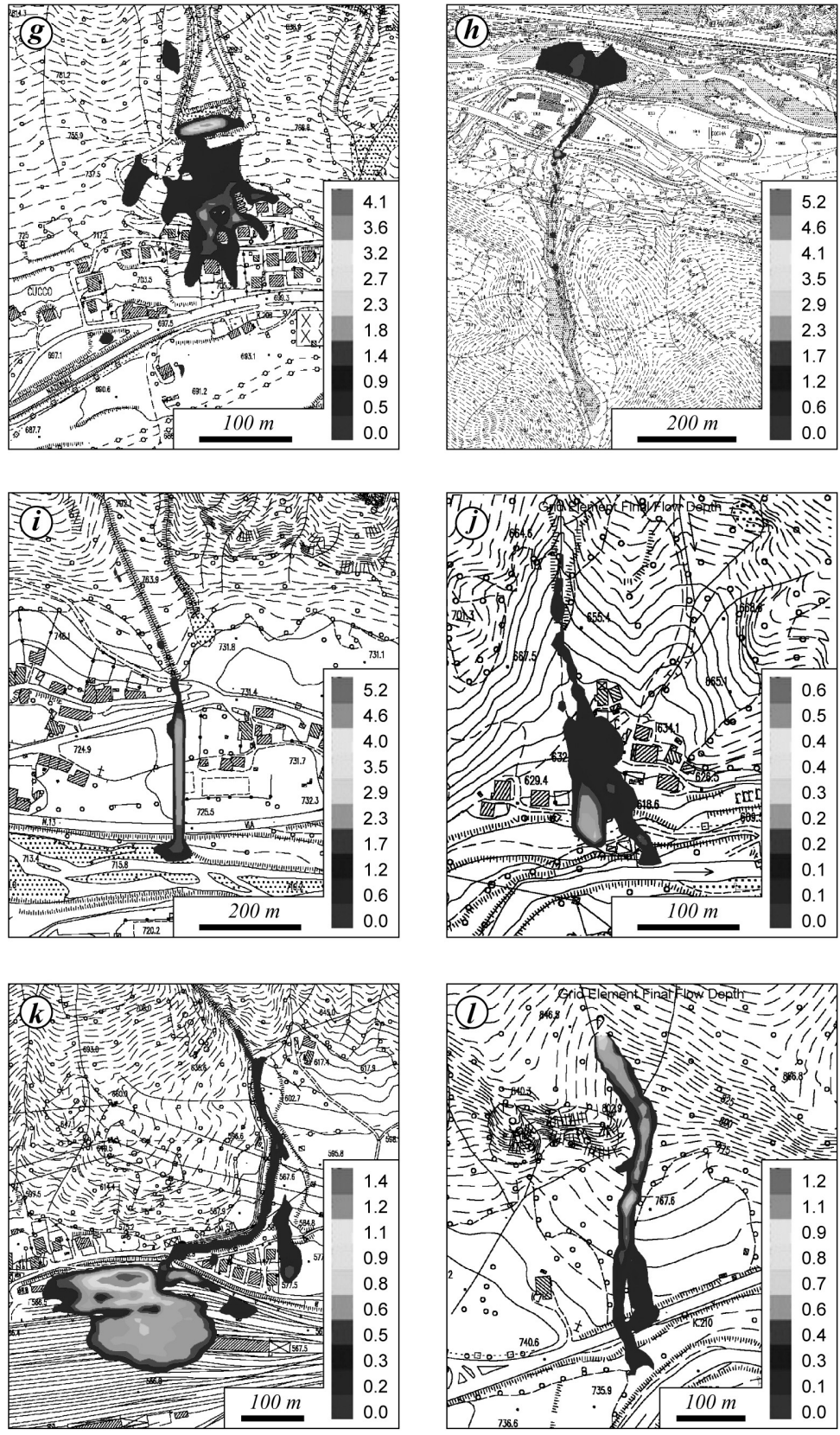

Figure 3: $\quad$ Final flow depth areas calculated for basins: g) Abitato Cucco, h) Rio Pirgler, i) Malborghetto nuovo, j) Studena Bassa, k) Rio Pontebba 2, 1) Malborghetto Est. 
of a future event. In the simulations made it has been noticed that DTM starting data are really important. Morphology of the invested area has to be perfectly recreated, otherwise the flow could reach zones that have not been invested during the event. This means that having available laser scanner data is a good starting point for an accurate simulation. This appeared more important on small scale basins like the ones available for this study. The maximum area involved has been of about 1,66 $\mathrm{km}^{2}$ (Rio Pirgler). Going on with the project, there has been several problems connected to the concentration by volume. In some basins, where the erosion has been substantial, many difficulties run up against calibrating the model in order to recreate the total volume stored on the floodplain. In the beginning, between the volume estimated during the surveys and the one obtained with the software there was a remarkable discrepancy. Later, adding more inflow points, it has been possible to insert all the debris involved in every single event. It is important not to forget that FLO-2D is not simulating the erosion (if you activate the mud/debris modality), so the flow is not increasing during its course, but it is only moving along the floodplain. For two of the twelve basins, during the simulations, we had a different approach. After the alluvial event of 1996, a lot of material has been removed, and the concentration by volume used for the simulation was too high (peak at 0.6), too much debris was flowing. A reduction in the $\mathrm{Cv}$ has been necessary just to increase the liquidity of the flow.

Concluding, every single phenomena has to be studied separately, according to its geological, geomorphological and rheological characteristics in order to reach a good consistency with the field data.

\section{References}

[1] Tropeano D., Turconi L., and Sanna S., Debris flows triggered by the 29 August 2003 cloudburst in Val Canale, eastern Italian Alps. Proc. Int. Symp. INTERPRAEVENT 2004, Riva del Garda, Italy, 2004.

[2] O'Brien J.S. and Julien P.Y., Physical properties and mechanics of hyperconcentrated sediment flows. Proc. ASCE Spec. Conf. on Delineation of Landslides, Flash Floods and Debris Flow Hazards in Utah, University of Utah at Logan, Utah, pp.260-279, 1985.

[3] Tecca P.R., Armento C. and Genevois R., Debris flow hazard and mitigation works in Fiames slope (Dolomites, Italy). WIT Transactions on Ecology and Environment, Vol. 90, pp.15-25, 2006.

[4] Borga et al., Hydrometeorological Analysis of the 29 August 2003 Flash Flood in the

[5] Eastern Italian Alps, American Meteorological Society, DOI: 10.1175/JHM593.1, 2007

[6] FLO-2D, 2-Dimensional Flood Routine Model Manual, Version 2006.

[7] D'Agostino V., Tecca P.R., Some considerations on the application of the FLO-2D model for debris flow hazard assessment, Monitoring, Simulations, Prevention and Remediation of Dense and Debris Flows, WIT Transactions on Ecology and Environment, Vol. 90, pp. 159-170, 2006. 